\title{
INCREASED PLASMA N-TERMINAL PRO-BNP IN NEONATES LESS THAN 32 WEEKS GESTATION WITH OPEN DUCTUS ARTERIOSUS
}

\author{
A. Sellmer ${ }^{1,2}$, J. Bjerre ${ }^{1}$, B.H. Bech ${ }^{3}$, V.E. Hjortdal ${ }^{4}$, T. Pedersen ${ }^{1}$, M.R. Schmidt ${ }^{5}$, T.B. Henriksen ${ }^{1,2}$ \\ ${ }^{1}$ Department of Paediatrics, ${ }^{2}$ Perinatal Epidemiology Research Unit, Aarhus University Hospital, ${ }^{3}$ School of \\ Public Health, Department of Epidemiology, Aarhus University, ${ }^{4}$ Department of Thoracic Surgery, \\ ${ }^{5}$ Department of Cardiology, Aarhus University Hospital, Aarhus, Denmark
}

Background and aims: To investigate the following:

1) the proportion of very preterm neonates that has an open ductus arteriosus (DA) on day four and

2) if plasma levels of N-terminal pro-B-type natriuretic peptide (NTpBNP) and high sensitive cardiac troponin $\mathrm{T}(\mathrm{cTnT})$ on day four differ in newborns with and without DA day seven.

Methods: All newborns ( $\mathrm{n}=80)$ with gestational age $(\mathrm{GA})<32$ weeks were recruited (January 2010 - March 2011). Echocardiography was performed on day four of life. Diameter of DA (dDA), peak systolic velocity in the DA $\left(\mathrm{v}_{\max }\right)$, and left atrial-aorta ratio (LAAo) were evaluated. NTpBNP and $\mathrm{cTnT}$ were measured $(\mathrm{n}=34)$. Medians are provided with 25 and 75 centiles.

Results: DA was open on day four in $38(48 \%)$ of children and open on day seven in 31 children. In neonates with a DA day four median dDA was $1.8 \mathrm{~mm}(1.2-2.3)$ and $\mathrm{v}_{\max } 2.2 \mathrm{~m} / \mathrm{s}$ (1.4-2.6), and the median LAAo was 1.4 (1.2-1.6). Neonates with an open DA day seven had on day four a higher median NTpBNP $7,369 \mathrm{ng} / 1$ (2,731-29,354) compared to neonates with a closed DA day seven 2,627 ng/1 (1,081$3,785)(\mathrm{p}=0.05)$. Median cTnT did not differ statistically between the groups (212 ng/l (92-190) vs. $323 \mathrm{ng} / 1$ (180-297)(ns).

Conclusions: Half of all very preterm neonates had an open DA on day four. Plasma levels of NTpBNP was found to be higher on day four in children with an open DA on day seven compared to children with closed DA. No difference in cTnT was found. 